\title{
Pharmacogenetic Aspects of Antipsychotic Drug-induced Weight Gain - A Critical Review
}

\author{
Gavin P. Reynolds \\ Biomedical Research Centre, Sheffield Hallam University, Sheffield, United Kingdom
}

\begin{abstract}
Treatment with several antipsychotic drugs can result in weight gain, which may lead to further morbidity such as type 2 diabetes and cardiovascular disease via the development of metabolic syndrome. These important and problematic metabolic consequences of antipsychotic drug treatment probably reflect a pharmacological disruption of the mechanisms involved in control of food intake and body weight. The extent of weight gain following antipsychotic drug treatment shows substantial variability between individuals, due in part to genetic factors. Common functional polymorphisms in many candidate genes implicated in the control of body weight and various aspects of energy and lipid metabolism have been investigated for association with weight gain in subjects receiving antipsychotic drug treatment, and with metabolic pathology in chronic schizophrenia. Perhaps the strongest and most replicated findings are the associations with promoter polymorphisms in the 5-HT2C receptor and leptin genes, although many other possible genetic risk factors, including polymorphisms in the fat mass and obesity associated (FTO) gene and genes for the alpha2A adrenoceptor and melanocortin4 receptor, have been reported. Genome-wide association studies (GWAS) have also addressed antipsychotic-induced weight gain and other indicators of metabolic disturbances. However there is as yet little consistency between these studies or between GWAS and classical candidate gene approaches. Identifying common genetic factors associated with drug-induced weight gain and its metabolic consequences may provide opportunities for personalized medicine in the predictive assessment of metabolic risk as well as indicating underlying physiological mechanisms.
\end{abstract}

KEY WORDS: Schizophrenia; Metabolic syndrome; Diabetes mellitus; Genetic polymorphism; Genetic association studies.

\section{INTRODUCTION}

There is no doubt that, despite their side effects and limited efficacy, antipsychotic drugs have provided relief and symptom control for a substantial proportion of people with schizophrenia and related psychotic disorders as well as, more recently, bipolar mania. The introduction of the second generation, "atypical" antipsychotics provided a further valuable advance. These drugs provide an improved tolerability, with a reduction in extrapyramidal motor symptoms, and some of these drugs also show evidence of increased efficacy.

However, along with the increased use of these second generation antipsychotics has come an increasing awareness of an important and limiting adverse effect, that of

\footnotetext{
Received: March 13, 2012 / Revised: April 28, 2012

Accepted: May 25, 2012

Address for correspondence: Gavin P. Reynolds, PhD

Biomedical Research Centre, Sheffield Hallam University, Howard

Street, Sheffield S1 1WB, United Kingdom

Tel: $+44-7740-651500$

E-mail:gavin.reynolds@hotmail.com
}

weight gain and its metabolic consequences. This is not particularly new; weight gain has been recognised as a side effect of antipsychotic drug treatment since the introduction of chlorpromazine in the 1950s. Although long recognised as problematic, the full impact of drug-induced weight gain on the physical and psychological health of those receiving antipsychotic drug treatment has only recently been fully acknowledged. One factor that perhaps obscured the importance of antipsychotic-induced weight gain was concern over motor side effects, which drove the development of the newer drugs. However, it is probably no coincidence that this has occurred when there is an increasing awareness of the "obesity epidemic" and its consequences for the general population.

But overweight is substantially more frequent in those receiving antipsychotic drug treatment than in the rest of the population. Yet its dangers are as great; it can rapidly develop into obesity, with concurrent dyslipidemia and impaired glucose tolerance which may eventually result in type II diabetes. A further consequence of these adverse 
effects can be cardiovascular disease, which is likely to contribute to the reduced life expectancy and increased incidence of cardiovascular death among people with severe mental illness. ${ }^{1)}$ Furthermore, the perception of weight gain as a result of taking antipsychotic drugs may contribute towards treatment non-adherence, with inevitable consequences in increasing risk of relapse. Thus antipsychotic drug-induced metabolic disturbance is one of the greatest concerns of current psychiatric pharmacotherapy.

The antipsychotic drugs demonstrate differences in the extent of the weight gain that they can induce. Some, like aripiprazole and ziprasidone show little effect above placebo levels, while olanzapine and clozapine can frequently induce profound weight gain; several other drugs including chlorpromazine, risperidone and quetiapine, show, on average, intermediate levels of weight gain., ${ }^{2,3)}$

It is very apparent to the practising clinician that there can be profound differences between individuals in their susceptibility to drug-induced weight gain and which cannot be explained by differences in drug treatment or life-style factors. Such individual differences strongly suggest the involvement of genetic factors, and this is supported by evidence from studies of siblings and twin pairs. Weight gain following antipsychotic treatment studied in pairs of siblings and monozygotic twins showed greater concordance in the twin pairs, interpreted as evidence for drug-induced weight gain having a strong genetic contribution, estimated at $60-80 \%$.

Thus pharmacogenetics, the study of the influence of genetic variation on the effects of drug treatment, has the potential to identify much of what may underlie individual differences in the metabolic consequences of antipsychotic treatment. This research has been progressing steadily and with some success for over a decade, although we have yet to reach the stage at which genetic testing can provide effective indicators of individual risk for drug-induced weight gain. This article will provide a brief review and critique of the major pharmacogenetic factors associated with this metabolic risk and how they may relate to the physiological mechanisms underlying their clinical effects. It will not therefore be an exhaustive and comprehensive review and listing of genetic association studies of antipsychotic weight gain, such as that recently published, ${ }^{5)}$ but will concentrate on the major replicated findings with some physiological relevance and on findings from the recent developments in methodology that drive pharmacogenomic research.

Initial research approaches identified common sites of variation, primarily single nucleotide polymorphisms (SNPs) or insertion/deletion sequences, in the DNA of one or a small number of "candidate" genes for study of their association with the clinical phenotype - in this case drug-induced weight gain. Choice of candidate genes is hypothesis-driven, whereby genes are usually selected on the basis of their coding for a protein that is known to be, or is potentially, involved in the functional effect of the drug and/or in the underlying physiological processes. Thus genetic factors can influence drug action in several ways, by being involved in pharmacokinetic processes or a variety of pharmacodynamics mechanisms including, but not necessarily restricted to, sites of drug action. ${ }^{6}$

Modern techniques have allowed pharmacogenetics to develop beyond the study of SNPs in one or a few candidate genes to the investigation of large numbers of genes across the whole of the genome, While these genome-wide association studies (GWAS) offer great power in identifying novel genetic associations they are not without limitations; as well as being free of hypotheses based on presumed mechanisms, they present difficulties in the handling and statistical analysis of large amounts of data.

\section{THE TARGET PHENOTYPES AND CANDIDATE GENES}

This review will concentrate primarily on genes related to pharmacodynamic mechanisms, although it is recognised that pharmacokinetic genes may also be strong candidates for influencing adverse metabolic effects. ${ }^{7)}$ Functional variants in metabolic enzymes, notably the widely-studied cytochrome P450 enzymes, can influence drug concentrations, drug availability and the ratio of active drug to metabolites (both active and inactive). Similarly, any functional genetic variability in systems influencing drug distribution, such as the p-glycoprotein pump, which can act to remove certain antipsychotic drugs from the brain, will also influence drug availability at sites of action. All effects on drug disposition will inevitably have effects on drug action, potentially influencing weight gain where this side effect is sensitive to drug concentration in the therapeutic range. ${ }^{6}$ To some extent pharmacokinetic variability may be ameliorated by dose titration, although this may not be true if drug effects are complicated by the presence of active metabolites. One aspect of studying pharmacodynamic gene candidates is that the findings can provide indications as to the underlying pharmacological and physiological mechanisms in a field that is as yet incompletely understood. 
The pharmacogenetics of weight gain and, to a lesser extent, its related metabolic consequences such as hyperlipidemia and type 2 diabetes have been investigated in some detail. The most-studied candidate genes derive from the underlying receptors considered to mediate drug effects on food intake ${ }^{8)}$ and at which several of the antipsychotic drugs may act: notably but not exclusively the serotonin 5-HT2C and histamine $\mathrm{H} 1$ receptors. In addition, further candidates are provided by the various proteins involved in the control of food intake, energy metabolism and fat deposition. These include circulating hormones such as leptin, ghrelin and adiponectin, the hypothalamic neuropeptides and related receptors, the cannabinoid system and other factors involved in glucose and lipid disposition and metabolism. ${ }^{8)}$

Where positive pharmacogenetic associations have been identified in such candidate genes, the precise mechanism whereby a SNP might result in effects on, say, food intake is rarely understood. The functional mechanisms of genetic polymorphisms are often uninvestigated. However it is often assumed, often without direct evidence, that they influence functional activity, expression or regulation of the gene product, or are in linkage disequilibrium with other SNPs that do so. The former effect might be true for certain missense coding region SNPs, while polymorphisms in 5' promoter sequences may affect the binding of transcription factors, thereby disrupting the control of gene expression and resulting in abnormal expression and regulation of the gene product. The same may be true of SNPs affecting microRNA sites in 3' regions, or those that have no clear functionality, such as synonymous SNPs in the coding region, but may influence transcript stability and disposition through effects on mRNA secondary structure. But it is important to reiterate that there is often no direct evidence for such effects and underlying mechanisms frequently remain obscure.

\section{PHARMACOGENETIC FINDINGS}

The first and most replicated study to demonstrate a clear, and relatively strong, pharmacogenetic association of a candidate gene with antipsychotic drug-induced weight gain investigated a 5-HT2C receptor gene (HTR2C) promoter polymorphism $(-759 \mathrm{C} / \mathrm{T})$ in drug-naive Chinese patients. After 10 weeks' treatment there was a highly significant association of genotype with weight gain in which those patients carrying the minor T allele $(22 \%$ of the sample) were protected from substantial $(>7 \%)$ gain in weight following initial treatment with risperidone or chlorpromazine with a relative risk of 3.45 . $^{9}$ This has, despite some failed replications, also been observed in several further studies including a European first-episode cohort receiving risperidone or olanzapine, ${ }^{10)}$ in chronic patients receiving olanzapine ${ }^{11)}$ and in patients receiving clozapine. ${ }^{12-14)}$ Thus the findings generalise to different drugs, including those with both high (clozapine and olanzapine) or relatively low (risperidone) affinity for the 5-HT2C receptor. A recent study and meta-analysis confirms the effect of the -759 SNP, and also indicates the missense polymorphism Ser23Cys associates with antipsychotic-induced weight gain. ${ }^{15)}$ However, this latter effect will have little influence in some ethnic sub-groups; the 23 Ser allele has a very low frequency in Asian populations. The -759C/T polymorphism, along with other promoter region polymorphisms of HTR2C with which it is in linkage disequilibrium, appears to be functional in influencing gene expression. ${ }^{16,17)}$

Another candidate gene repeatedly demonstrating a positive association with antipsychotic drug-induced weight gain is that for leptin, an anorexigenic hormone secreted by adipose tissue. This gene has a promoter region polymorphism influencing the secretion of leptin and which is associated with obesity. ${ }^{18)}$ In two drug-naive populations also investigated for the HTR2C association, antipsychotic weight gain was associated with this $-2548 \mathrm{~A} / \mathrm{G}$ polymorphism, ${ }^{10,19)}$ although in each study its influence on weight gain emerges later than that of the HTR2C SNP, findings which may differentiate initial and longer term effects on drug-induced physiological changes resulting in fat deposition. These findings have been confirmed in many further reports of antipsychotic-induced weight gain and obesity; one recent study in a large Taiwanese sample exemplifies this in showing the leptin -2548A/G polymorphism associated with measures of obesity and other metabolic pathology in patients with schizophrenia. ${ }^{20)}$ Authors of a recent report ${ }^{21)}$ have pointed out the discrepancies between studies - for example the two papers cited above report opposite effects of the $-2548 \mathrm{~A} / \mathrm{G}$ genotypes influencing weight gain - and suggest heterosis (with a greater effect of the heterozygous genotype than either homozygote) may underlie the inconsistencies observed, although ethnicity or other factors may play a role. Calculations from the combined leptin and HTR2C genotype effect reported by Templeman et al. ${ }^{10)}$ indicate that, along with baseline measures of body mass index, this genetic variability can account for a substantial proportion of the variance in weight gain. Interestingly, this study indicated that both the HTR2C and leptin SNPs influence leptin se- 
cretion as determined by its blood concentrations. As well as supporting a role for leptin in the mechanism of antipsychotic drug-induced weight gain, this finding points to an unexplored influence of the 5-HT2C receptor on leptin secretion.

Recent advances in the pharmacogenetics of antipsychotic-induced weight gain have been comprehensively reviewed elsewhere; ${ }^{5)}$ here I shall highlight some of the more interesting findings which may be understood in terms of possible physiological mechanisms. While the 5-HT2C receptor and leptin genes have accumulated the most consistent evidence in support of their roles as risk factors for antipsychotic-induced weight gain, a large number of further candidate genes have been investigated, notably those for other receptors that may mediate some of the metabolic effects of antipsychotic drugs. Unsurprisingly there have been many negative findings, including importantly SNPs in genes for the dopamine $\mathrm{D}{ }^{22)}$ and histamine $\mathrm{H} 1$ receptors ${ }^{23}$ ) although both of these also have more recent positive reports. ${ }^{24,25}$

Other candidates that have demonstrated replicated positive associations with weight gain on antipsychotic drugs include the $\alpha 2 \mathrm{~A}$ adrenoceptor gene ${ }^{26)}$ and two factors relating to synaptic transmission: SNAP $25^{27)}$ and the G-protein beta3 subunit (GNB3) genes. ${ }^{28,29)}$ Evidence for an effect of HTR2A SNPs on antipsychotic-induced weight gain has been inconsistent, although a study carried out on patients treated with olanzapine showed that a combination of HTR2A and HTR2C SNPs with SNPs in GNB3 and the beta3 adrenoceptor gene were associated with olanzapine-induced weight gain, with significant additive effects. ${ }^{30)}$ Brain-derived neurotrophic factor (BDNF) has a role in the regulation of food intake and there is a reported association of the functional val66met SNP in males. ${ }^{31)}$ Similarly the role of cannabinoids in food intake and appetite is likely to underlie the reported associations of genes for the CB1 receptor ${ }^{32)}$ and fatty acid amide hydrolase $^{33)}$ in antipsychotic weight gain. Very recently, SNPs in the melanocortin4 receptor gene, a risk factor for obesity, have been shown to be associated with antipsychotic-induced weight gain in both treatment-naïve and chronic subjects ${ }^{5}$ and a measure of obesity. ${ }^{20)}$ Another risk factor for obesity, the fat mass and obesity associated (FTO) gene, is reportedly not associated with initial weight gain in first-episode patients; ${ }^{34)}$ in very recent findings we confirm this observation but also find that it is associated with body mass in chronically-treated patients, where the effect of the FTO gene appears substantially enhanced after long term treatment with antipsychotic drugs
(Reynolds et al., unpublished observations). The important and independent Clinical Antipsychotic Trials in Intervention Effectiveness (CATIE) trial of the relative effects of several antipsychotic drugs ${ }^{35}$ is a valuable sample source for pharmacogenetic studies. A recent study of this cohort also identified an association of weight gain with a SNP in FTO, as well as with two other significant genes. ${ }^{36)}$

Results from GWAS and other multiple SNP approaches contrast substantially with those from such studies of single candidate genes. The first genome-wide linkage study was successful in identifying a possible genetic indicator underlying antipsychotic drug-induced obesity. ${ }^{37)}$ These authors identified linkage in the region of the gene for pro-melanin-concentrating hormone, which is involved in the hypothalamic control of food intake; a subsequent study identified association of obesity in patients treated with olanzapine with a polymorphism in this candidate gene. ${ }^{38)}$

The CATIE cohort has also been investigated by GWAS for pharmacogenetic associations with a variety of metabolic outcomes. ${ }^{39)}$ Unfortunately, none of the genes associated with the 21 SNPs identified as significant in this report had previously been found to associate with metabolic consequences of antipsychotic drug treatment, even in studies employing the same sample! $!^{36)}$ However two of these genes, MEIS2 and PRKAR2B, respectively associated with risperidone effects on waist and hip circumference and clozapine effects on triglycerides, have reportedly been previously implicated in metabolic function. $^{39)}$

Genetic factors in genes that influence serum lipids, such as those for apolipoprotein and lipoprotein lipase, have been studied in one report, with small associations with weight gain being identified. ${ }^{40)}$ A DNA microarray candidate-gene approach has led to the identification of further genetic factors that might contribute to antipsychotic-induced hyperlipidemia, with polymorphisms in genes for acetyl-coenzyme A carboxylase $\alpha$ and neuropeptide $\mathrm{Y}$ emerging as promising candidates. ${ }^{41)}$ Antipsychotics interact with genes controlled by sterol regulatory binding element protein transcription factors, ${ }^{42)}$ and a strong association has been identified between antipsychotic-induced weight gain and polymorphisms in one of these transcription factors, also a risk gene for obesity, insulin-induced gene $2 .{ }^{43)}$ Although this finding is not fully replicated, ${ }^{44)}$ others have reported association of this gene with metabolic pathology including elevated fasting plasma glucose. ${ }^{20)}$

An elevation in fasting glucose is indicative of glucose 
intolerance, a precursor of diabetes. There have been relatively few investigations into the genetic factors determining the individual differences in liability to antipsychotic drug-induced diabetes. There are at least two different processes here: that associated with the often acute onset, reversible diabetes occurring independent of elevations in body fat mass and underlying the rare occurrences of ketoacidosis, and the type 2 diabetes that is a long-term consequence of obesity and the development of metabolic syndrome. Although these are two different physiological consequences of drug treatment, it is notable that the drugs with the greatest effect on weight gain, clozapine and olanzapine, are also particularly associated with the rapid-onset diabetes. ${ }^{45)}$ This acute effect has not been investigated genetically; the longer-term consequences have been studied primarily in terms of the emergence of metabolic syndrome. One study reported an association with the leptin promoter SNP, but not with the -759C/T HTR2C $\mathrm{SNP} ;^{46)}$ however an interaction between the two polymorphisms was observed. Another group did find, and replicated, association of metabolic syndrome with another HTR2C SNP ${ }^{47)}$ and with the $\alpha 2 \mathrm{~A}$ adrenoceptor gene. ${ }^{48)}$

\section{CONCLUSIONS}

Substantial effort has been spent in attempting to determine the genetic associations with the metabolic consequences of antipsychotic drug treatment, in the search for predictive factors that might be used to identify individual risk of these problematic adverse effects. As yet, only a few risk factors have been reproducibly identified in candidate gene studies, including SNPs in the leptin and HTR2C genes, and none of these genes have consistently emerged from GWAS.

Such variability and apparent inconsistency is common throughout the pharmacogenetic literature; as yet the larger GWAS have not proven to be more reliable in providing consistent findings. There are many reasons for this; one important factor is that many studies do not have the statistical power to identify what are often relatively small effects and which will inevitably introduce variability between studies. Sample differences in terms of ethnicity are an obvious further factor, while differences in treatment history and, important for the current topic, in diet and other life style factors may also contribute.

Future work will thus need to resolve these many inconsistences and discrepancies between studies that are apparent in the current literature. Despite the rapid advancements in technology, research approaches remain some- what naïve; there will need to be a greater recognition that analysis of additive gene effects, gene-gene interactions and perhaps also gene-environment interactions will be important in understanding properly the various genetic risk factors contributing to the emergence of drug-induced metabolic pathology. However, as the opportunity for genotyping large numbers of SNPs in large samples becomes cheaper and more accessible, findings from further GWAS studies will, we hope, converge to give us consistent results. Identifying such results will open up opportunities for predictive genetic testing in personalised medicine, once the validity and, importantly, utility in the clinic of this pharmacogenetic approach are established. Moreover, while we recognise that candidate genes are often chosen on the basis of a known relationship with the mechanism of drug action, identifying novel genetic associations with weight gain and metabolic pathology may well provide clues as to the underlying pharmacological and physiological processes.

\section{REFERENCES}

1. Osborn DP, Levy G, Nazareth I, Petersen I, Islam A, King MB. Relative risk of cardiovascular and cancer mortality in people with severe mental illness from the United Kingdom's General Practice Rsearch Database. Arch Gen Psychiatry 2007;64:242-249.

2. Allison DB, Mentore JL, Heo M, Chandler LP, Cappelleri JC, Infante MC, et al. Antipsychotic-induced weight gain: a comprehensive research synthesis. Am J Psychiatry 1999; 156:1686-1696.

3. Parsons B, Allison DB, Loebel A, Williams K, Giller E, Romano $\mathrm{S}$, et al. Weight effects associated with antipsychotics: a comprehensive database analysis. Schizophr Res 2009;110:103-110.

4. Gebhardt S, Theisen FM, Haberhausen M, Heinzel-Gutenbrunner M, Wehmeier PM, Krieg JC, et al. Body weight gain induced by atypical antipsychotics: an extension of the monozygotic twin and sib pair study. J Clin Pharm Ther 2010;35:207-211.

5. Lett TA, Wallace TJ, Chowdhury NI, Tiwari AK, Kennedy JL, Müller DJ. Pharmacogenetics of antipsychotic-induced weight gain: review and clinical implications. Mol Psychiatry 2012;17:242-266.

6. Reynolds GP. The impact of pharmacogenetics on the development and use of antipsychotic drugs. Drug Discov Today 2007; 12:953-959.

7. Arranz MJ, de Leon J. Pharmacogenetics and pharmacogenomics of schizophrenia: a review of last decade of research. Mol Psychiatry 2007;12:707-747.

8. Reynolds GP, Kirk SL. Metabolic side effects of antipsychotic drug treatment-pharmacological mechanisms. Pharmacol Ther 2010;125:169-179.

9. Reynolds GP, Zhang ZJ, Zhang XB. Association of antipsychotic drug-induced weight gain with a 5-HT2C receptor gene polymorphism. Lancet 2002;359:2086-2087.

10. Templeman LA, Reynolds GP, Arranz B, San L. Polymorphisms of the 5-HT2C receptor and leptin genes are 
associated with antipsychotic drug-induced weight gain in Caucasian subjects with a first-episode psychosis. Pharmacogenet Genomics 2005;15:195-200.

11. Ellingrod VL, Perry PJ, Ringold JC, Lund BC, Bever-Stille $\mathrm{K}$, Fleming $\mathrm{F}$, et al. Weight gain associated with the $-759 C / T$ polymorphism of the 5HT2C receptor and olanzapine. Am J Med Genet B Neuropsychiatr Genet 2005; 134B:76-78.

12. Miller DD, Ellingrod VL, Holman TL, Buckley PF, Arndt S. Clozapine-induced weight gain associated with the 5HT2C receptor-759C/T polymorphism. Am J Med Genet B Neuropsychiatr Genet 2005;133B:97-100.

13. Reynolds GP, Zhang Z, Zhang X. Polymorphism of the promoter region of the serotonin 5-HT(2C) receptor gene and clozapine-induced weight gain. Am J Psychiatry 2003; 160:677-679.

14. Chung YI, Shin DH, Kim CM, Kim HJ. Association between clozapine-induced weight gain and serotonin 5-HT2C receptor gene polymorphism in Korean schizophrenic patients. Clin Psychopharmacol Neurosci 2004;2:11-15.

15. Sicard MN, Zai CC, Tiwari AK, Souza RP, Meltzer HY, Lieberman JA, et al. Polymorphisms of the HTR2C gene and antipsychotic-induced weight gain: an update and metaanalysis. Pharmacogenomics 2010;11:1561-1571.

16. Hill MJ, Reynolds GP. Functional consequences of two HTR2C polymorphisms associated with antipsychotic-induced weight gain. Pharmacogenomics 2011;12:727-734.

17. Hill MJ, Reynolds GP. 5-HT2C receptor gene polymorphisms associated with antipsychotic drug action alter promoter activity. Brain Res 2007;1149:14-17.

18. Mammès $\mathrm{O}$, Betoulle $\mathrm{D}$, Aubert $\mathrm{R}$, Herbeth $\mathrm{B}$, Siest G, Fumeron F. Association of the G-2548A polymorphism in the 5' region of the LEP gene with overweight. Ann Hum Genet 2000;64:391-394.

19. Zhang ZJ, Zhang XB, Sha WW, Zhang XB, Reynolds GP. Association of a polymorphism in the promoter region of the serotonin 5-HT2C receptor gene with tardive dyskinesia in patients with schizophrenia. Mol Psychiatry 2002;7:670-671.

20. Kuo PH, Kao CF, Chen PY, Chen CH, Tsai YS, Lu ML, et al. Polymorphisms of INSIG2, MC4R, and LEP are associated with obesity- and metabolic-related traits in schizophrenic patients. J Clin Psychopharmacol 2011;31: 705-711.

21. Brandl EJ, Frydrychowicz C, Tiwari AK, Lett TA, Kitzrow $\mathrm{W}$, Büttner S, et al. Association study of polymorphisms in leptin and leptin receptor genes with antipsychotic-induced body weight gain. Prog Neuropsychopharmacol Biol Psychiatry 2012. [Epub ahead of print]

22. Zhang ZJ, Yao ZJ, Zhang XB, Chen JF, Sun J, Yao H, et al. No association of antipsychotic agent-induced weight gain with a DA receptor gene polymorphism and therapeutic response. Acta Pharmacol Sin 2003;24:235-240.

23. Hong CJ, Lin CH, Yu YW, Chang SC, Wang SY, Tsai SJ. Genetic variant of the histamine-1 receptor (glu349asp) and body weight change during clozapine treatment. Psychiatr Genet 2002;12:169-171.

24. Lencz T, Robinson DG, Napolitano B, Sevy S, Kane JM, Goldman $\mathrm{D}$, et al. DRD2 promoter region variation predicts antipsychotic-induced weight gain in first episode schizophrenia. Pharmacogenet Genomics 2010;20:569-572.

25. Vehof J, Risselada AJ, Al Hadithy AF, Burger H, Snieder $\mathrm{H}$, Wilffert $\mathrm{B}$, et al. Association of genetic variants of the histamine $\mathrm{HI}$ and muscarinic M3 receptors with BMI and HbAlc values in patients on antipsychotic medication. Psychopharmacology (Berl) 2011;216:257-265.
26. Park YM, Chung YC, Lee SH, Lee KJ, Kim H, Byun YC, et al. Weight gain associated with the alpha2a-adrenergic receptor $-1,291$ C/G polymorphism and olanzapine treatment. Am J Med Genet B Neuropsychiatr Genet 2006;141B: 394-397.

27. Müller DJ, Klempan TA, De Luca V, Sicard T, Volavka J, Czobor $\mathrm{P}$, et al. The SNAP-25 gene may be associated with clinical response and weight gain in antipsychotic treatment of schizophrenia. Neurosci Lett 2005;379:81-89.

28. Bishop JR, Ellingrod VL, Moline J, Miller D. Pilot study of the G-protein beta3 subunit gene (C825T) polymorphism and clinical response to olanzapine or olanzapine-related weight gain in persons with schizophrenia. Med Sci Monit 2006; 12:BR47-BR50.

29. Wang YC, Bai YM, Chen JY, Lin CC, Lai IC, Liou YJ. C825T polymorphism in the human $G$ protein beta 3 subunit gene is associated with long-term clozapine treatmentinduced body weight change in the Chinese population. Pharmacogenet Genomics 2005;15:743-748.

30. Ujike H, Nomura A, Morita Y, Morio A, Okahisa Y, Kotaka $\mathrm{T}$, et al. Multiple genetic factors in olanzapine-induced weight gain in schizophrenia patients: a cohort study. J Clin Psychiatry 2008;69:1416-1422.

31. Zhang XY, Zhou DF, Wu GY, Cao LY, Tan YL, Haile CN, et al. BDNF levels and genotype are associated with antipsychotic-induced weight gain in patients with chronic schizophrenia. Neuropsychopharmacology 2008;33:2200-2205.

32. Tiwari AK, Zai CC, Likhodi O, Lisker A, Singh D, Souza $\mathrm{RP}$, et al. A common polymorphism in the cannabinoid receptor 1 (CNRI) gene is associated with antipsychoticinduced weight gain in Schizophrenia. Neuropsychopharmacology 2010;35:1315-1324.

33. Monteleone P, Milano W, Petrella C, Canestrelli B, Maj M. Endocannabinoid Pro129Thr FAAH functional polymorphism but not 1359G/A CNR1 polymorphism is associated with antipsychotic-induced weight gain. J Clin Psychopharmacol 2010;30:441-445.

34. Perez-Iglesias R, Mata I, Amado JA, Berja A, GarciaUnzueta MT, Martínez García O, et al. Effect of FTO, SH2B1, LEP, and LEPR polymorphisms on weight gain associated with antipsychotic treatment. J Clin Psychopharmacol 2010;30:661-666.

35. Lieberman JA, Stroup TS, McEvoy JP, Swartz MS, Rosenheck RA, Perkins DO, et al; Clinical Antipsychotic Trials of Intervention Effectiveness (CATIE) Investigators. Effectiveness of antipsychotic drugs in patients with chronic schizophrenia. N Engl J Med 2005;353:1209-1223.

36. Tiwari HK, Patki A, Lieberman J, Stroup TS, Allison DB, Leibel RL, et al. Association of allelic variation in genes mediating aspects of energy homeostasis with weight gain during administration of antipsychotic drugs (CATIE Study). Front Genet 2011;2(56). pii: 00056.

37. Chagnon YC, Mérette C, Bouchard RH, Emond C, Roy MA, Maziade M. A genome wide linkage study of obesity as secondary effect of antipsychotics in multigenerational families of eastern Quebec affected by psychoses. Mol Psychiatry 2004;9:1067-1074.

38. Chagnon YC, Bureau A, Gendron D, Bouchard RH, Mérette $\mathrm{C}$, Roy MA, et al. Possible association of the pro-melaninconcentrating hormone gene with a greater body mass index as a side effect of the antipsychotic olanzapine. Am J Med Genet B Neuropsychiatr Genet 2007;144B:1063-1069.

39. Adkins DE, Aberg K, McClay JL, Bukszár J, Zhao Z, Jia $\mathrm{P}$, et al. Genomewide pharmacogenomic study of metabolic side effects to antipsychotic drugs. Mol Psychiatry 2011; 
16:321-332.

40. Smith RC, Segman RH, Golcer-Dubner T, Pavlov V, Lerer B. Allelic variation in ApoC3, ApoA5 and LPL genes and first and second generation antipsychotic effects on serum lipids in patients with schizophrenia. Pharmacogenomics $J$ 2008;8:228-236.

41. de Leon J, Correa JC, Ruaño G, Windemuth A, Arranz MJ, Diaz FJ. Exploring genetic variations that may be associated with the direct effects of some antipsychotics on lipid levels. Schizophr Res 2008;98:40-46.

42. Fernø J, Raeder MB, Vik-Mo AO, Skrede S, Glambek M, Tronstad KJ, et al. Antipsychotic drugs activate SREBPregulated expression of lipid biosynthetic genes in cultured human glioma cells: a novel mechanism of action? Pharmacogenomics $J$ 2005;5:298-304.

43. Le Hellard S, Theisen FM, Haberhausen M, Raeder MB, Fernø J, Gebhardt S, et al. Association between the insulininduced gene 2 (INSIG2) and weight gain in a German sample of antipsychotic-treated schizophrenic patients: perturbation of SREBP-controlled lipogenesis in drug-related metabolic adverse effects? Mol Psychiatry 2009;14:308-317.

44. Tiwari AK, Zai CC, Meltzer HY, Lieberman JA, Müller DJ,
Kennedy JL. Association study of polymorphisms in insulin induced gene 2 (INSIG2) with antipsychotic-induced weight gain in European and African-American schizophrenia patients. Hum Psychopharmacol 2010;25:253-259.

45. Newcomer JW. Second-generation (atypical) antipsychotics and metabolic effects: a comprehensive literature review. CNS Drugs 2005;19(Suppl 1):1-93.

46. Yevtushenko OO, Cooper SJ, O'Neill R, Doherty JK, Woodside JV, Reynolds GP. Influence of 5-HT2C receptor and leptin gene polymorphisms, smoking and drug treatment on metabolic disturbances in patients with schizophrenia. $\mathrm{Br}$ J Psychiatry 2008;192:424-428.

47. Risselada AJ, Vehof J, Bruggeman R, Wilffert B, Cohen D, $\mathrm{Al}$ Hadithy $\mathrm{AF}$, et al. Association between HTR2C gene polymorphisms and the metabolic syndrome in patients using antipsychotics: a replication study. Pharmacogenomics $J$ 2012;12:62-67.

48. Risselada AJ, Vehof J, Bruggeman R, Wilffert B, Cohen D, Al Hadithy AF, et al. Association between the 1291-C/G polymorphism in the adrenergic $\alpha-2 a$ receptor and the metabolic syndrome. J Clin Psychopharmacol 2010;30:667671. 